\title{
Molecular Mechanisms of Cell Segregation and Boundary Formation in Development and Tumorigenesis
}

\author{
Eduard Batlle ${ }^{1}$ and David G. Wilkinson ${ }^{2}$ \\ ${ }^{1}$ Oncology Program and ICREA, Institute for Research in Biomedicine, Josep Samitier 1-5, 08028 Barcelona, Spain \\ ${ }^{2}$ Division of Developmental Neurobiology, MRC National Institute for Medical Research, The Ridgeway, Mill Hill, \\ London NW7 1AA, United Kingdom \\ Correspondence:dwilkin@nimr.mrc.ac.uk
}

\section{SUMMARY}

The establishment and maintenance of precisely organized tissues requires the formation of sharp borders between distinct cell populations. The maintenance of segregated cell populations is also required for tissue homeostasis in the adult, and deficiencies in segregation underlie the metastatic spreading of tumor cells. Three classes of mechanisms that underlie cell segregation and border formation have been uncovered. The first involves differences in cadherin-mediated cell-cell adhesion that establishes interfacial tension at the border between distinct cell populations. A second mechanism involves the induction of actomyosin-mediated contraction by intercellular signaling, such that cortical tension is generated at the border. Third, activation of Eph receptors and ephrins can lead to both decreased adhesion by triggering cleavage of E-cadherin, and to repulsion of cells by regulation of the actin cytoskeleton, thus preventing intermingling between cell populations. These mechanisms play crucial roles at distinct boundaries during development, and alterations in cadherin or Eph/ephrin expression have been implicated in tumor metastasis.

\section{Outline}

1 Introduction

2 Cell adhesion and differential affinity

3 Regulation of cell migration by cadherins

4 Roles of cell cortex tension

5 Cell segregation by Eph-ephrin signaling
6 Cell adhesion and tissue boundaries as suppressors of tumor progression

7 Concluding remarks

References

Editors: Patrick P.L. Tam, W. James Nelson, and Janet Rossant

Additional Perspectives on Mammalian Development available at www.cshperspectives.org

Copyright (C 2012 Cold Spring Harbor Laboratory Press; all rights reserved; doi: 10.1101/cshperspect.a008227

Cite this article as Cold Spring Harb Perspect Biol 2012;4:a008227 


\section{INTRODUCTION}

The generation of a functional organism requires the formation and maintenance of a precise organization of different tissues and of distinct cell types within tissues. For many tissues, establishment of the final complex pattern involves an initial subdivision into regions, each with a specific identity that underlies the subsequent generation of a particular set of cell types. Such spatial patterning is achieved in part through localized cell-to-cell signaling that induces specific tissues, regional domains, or cell types to form at the appropriate location. However, these patterns are initially imprecise and undergo refinement, for example, by sharpening of a fuzzy border between tissue subdivisions. Furthermore, the emerging patterns can potentially become scrambled owing to the intrinsic motility of many cells, and because tissue growth and morphogenesis can drive intermingling; for example, cell intercalation during proliferation or convergence-extension movements can disperse clonally related cells. The control of cell movement to generate and maintain the precision of tissue organization is thus of central importance in embryogenesis, as well as in tissue homeostasis in the adult organism. A failure to maintain the correct localization of cells underlies clinically relevant disorders such as the metastatic spreading of tumors. There is consequently much interest in identifying the underlying cellular and molecular mechanisms.

Mechanisms that establish and maintain tissue organization have been intensively studied for the sharp boundaries that form at the interface of adjacent tissues and of regional domains within a tissue. Insights into the significance of boundary formation came from studies of embryogenesis and wing imaginal disc development in Drosophila that revealed the existence of compartments (groups of cells that do not intermingle with their neighbors), thus enabling each territory to maintain a discrete regional identity (reviewed by Irvine and Rauskolb 2001). Compartments have also been identified in vertebrate tissues, for example, in the developing nervous system, in which the intermingling of cells is restricted across the borders of specific subdivisions of the brain (Fraser et al. 1990; Zeltser et al. 2001; Langenberg and Brand 2005). The establishment of a sharp border can have a crucial role in addition to the generation of discrete regions: At some borders, specialized boundary cells form that act as a signaling center that further patterns the tissue, for example, by inducing distinct cell types at different concentrations of the signal (Irvine and Rauskolb 2001; Kiecker and Lumsden 2005). The formation of a sharp interface is thus essential for correct localization of the signaling center and patterning of the tissue (Dahmann and Basler 1999).
Important insights into how borders can form came from classic experiments in which cells from different tissues are dissociated, mixed, and allowed to reaggregate (reviewed by Steinberg 1963, 1970). It was found that the cells from distinct tissues segregate from each other to attain a characteristic organization in which one population envelops the other (Fig. 1A). Although such large-scale segregation generally does not occur in normal tissues, local segregation does occur at borders that are initially imprecise (Fig. 1B). A corollary to the process of segregation is that this will prevent the tissues from intermingling. It is therefore reasonable to assume that mechanisms that drive segregation in vitro contribute to the formation and maintenance of borders in vivo.

Studies using cell reaggregation assays led to the important and influential proposal that the differential adhesion of distinct cell populations underlies cell segregation (Steinberg 1970, 2007). However, other studies have uncovered distinct mechanisms that can restrict intermingling between cell populations, namely, the contact inhibition of cell migration, contact repulsion of cells by Eph receptor and ephrin signaling, and the induction of cortical tension (Abercrombie 1979; Poliakov et al. 2004; Dahmann et al. 2011). In this article, we will discuss the roles and relationships of these mechanisms in cell segregation and border maintenance during development and tumorigenesis. There is good evidence that some of these mechanisms also establish finer-grained patterns of distinct cell types, underlie matching of neurons to targets, and contribute to morphogenetic movements such as convergent extension (reviewed by Takeichi et al. 1997; Poliakov et al. 2004; Solnica-Krezel 2006; Rebsam and Mason 2011).

\section{CELL ADHESION AND DIFFERENTIAL AFFINITY}

The segregation of cells derived from different tissues in reaggregation assays was initially suggested to occur through a combination of directed cell migration and the selective adhesion of cells of the same type (Townes and Holtfreter 1955). Subsequent work from Steinberg and colleagues supported an alternative idea, formalized as the differential adhesion hypothesis, in which cells are proposed to have a liquidlike behavior: Nondirectional motility allows cells to reorganize, and differences in cell adhesion generate mechanical forces that drive segregation (Steinberg 1963; Steinberg 1970). The subsequent identification and functional experiments with cell adhesion molecules that mediate homophilic binding have provided strong support for a role of differential adhesion in cell segregation.

Cell-to-cell adhesion is mediated by a number of classes of proteins present on the cell surface that bind in trans to partners presented on adjacent cells (Yagi and Takeichi 2000; 

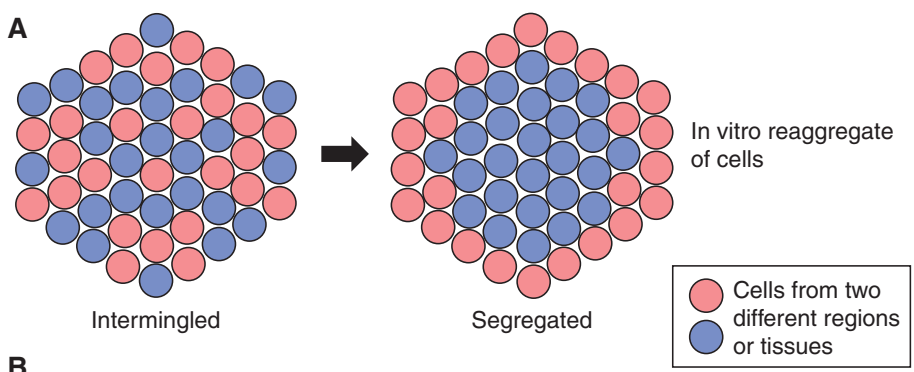

B

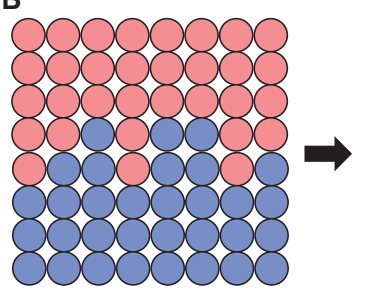

Fuzzy border

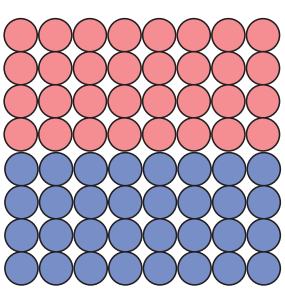

Sharp border

Border formation

at interface

\begin{abstract}
Figure 1. Cell segregation and boundary formation. (A) In vitro assay for cell segregation in which two cell populations are dissociated, mixed, and reaggregated. Over a period of time, the intermingled cell populations may segregate from each other. When performed with one population expressing lower levels of cadherin (red) than the other (blue), the former segregate to the outer region of the reaggregate, as predicted by the differential adhesion hypothesis. (B) During normal development, distinct tissues or regional domains within tissues are induced to form at specific locations. In many cases, the border of the adjacent domains is initially fuzzy, and local cell segregation underlies the formation of a sharp interface.
\end{abstract}

Halbleib and Nelson 2006; Harris and Tepass 2010). Prominent roles are played by "classical" cadherins, members of the cadherin superfamily of transmembrane proteins that also include protocadherins, Fat and dachsous, and the seven-pass membrane protein, Flamingo. Classical cadherins mediate homophilic binding, and in some cases also interact heterophilically with other family members. The specificity of cell responses to homophilic versus heterophilic interactions is determined not only by the binding interface (Patel et al. 2006) but also by other domains of the cadherin molecule (Niessen and Gumbiner 2002; Leckband and Prakasam 2006; Shi et al. 2008). On binding, cadherins trigger intracellular signaling that stimulates further recruitment of cadherins and thus increases the strength of adhesion (Ehrlich et al. 2002; Yamada and Nelson 2007). The cytoplasmic domain of cadherins interacts with proteins, including p120, $\beta$-catenin, and $\alpha$-catenin, that in turn bind the actin cytoskeleton or regulate its polymerization (Halbleib and Nelson 2006). The relationship between cadherins and the actin cytoskeleton is required for strong adhesion (Jamora and Fuchs 2002), and involves a dynamic exchange of binding partners rather than direct linkage (Drees et al. 2005; Yamada et al. 2005).

\subsection{Role of Differential Adhesion in Cell Segregation}

Key evidence in support of the differential adhesion hypothesis comes from reaggregation experiments showing that cells transfected to express different homophilically binding cadherins, or different levels of the same cadherin, will segregate from each other (Nose et al. 1988; Steinberg and Takeichi 1994). It is proposed that segregation is driven by mechanical forces of affinity and tension, analogous to those that occur at the molecular level for oil and water. A difference in affinity between two cell populations leads to tension at their interface because cells of one or both populations experience stronger cohesive forces from "like" cells (homotypic interactions) than from "unlike" cells (heterotypic interactions). In principle, this imbalance in forces will drive segregation to generate and maintain a flat interface-which minimizes contact between the two cell populations-as it requires an increase in free energy for a cell to break the stronger contacts with like cells to move into the unlike territory (Fig. 2A). A prediction is that in reaggregation assays, interfacial tension will drive the segregation of the more cohesive population to the center, and many studies have shown that indeed this is generally the outcome (Steinberg 1970, 2007; Steinberg and Takeichi 1994; Foty and Steinberg 2005).

Many cadherin family members have tissue- or regionally restricted expression during development (Matsunami and Takeichi 1995; Redies and Takeichi 1996; Inoue et al. 1997; Takeichi et al. 1997), suggestive of roles in cell segregation in vivo, and this has received strong support from a number of studies. For example, ectopic expression experiments have shown a role of R-cadherin and cadherin- 
A

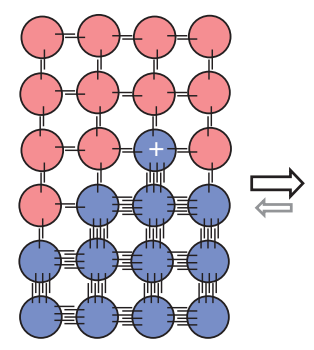

Fuzzy interface

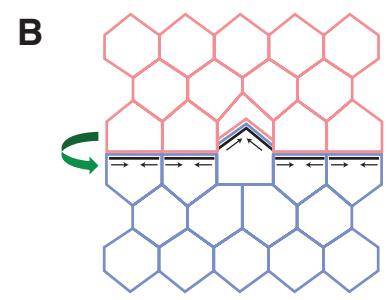

Kink in border

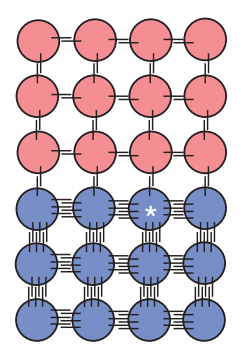

Smooth interface

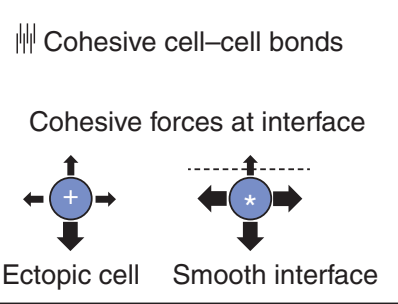

Ectopic cell Smooth interface

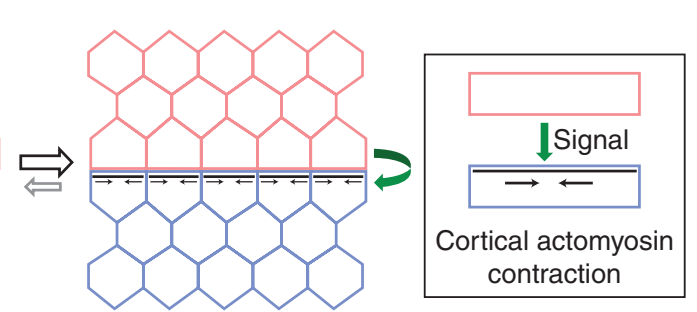

Straight border

Figure 2. Cell adhesion and cortical tension. (A) One mechanism underlying cell segregation is mediated by differential adhesion of the two distinct cell populations. The differential adhesion hypothesis proposes that segregation is driven by the aggregate achieving the lowest free energy in which there is maximal contact between cells with the higher mutual affinity. At the interface of the two populations, interfacial tension occurs because the more adhesive cells (blue) will experience stronger cohesive forces from "like" cells than from "unlike" cells (red). The cohesive forces experienced by an ectopic cell $(+)$ or by a cell at a smooth interface $\left({ }^{*}\right)$ are illustrated. At a fuzzy interface there is a net decrease in cohesive bonds and increase in free energy compared with a smooth interface. $(B)$ Another mechanism that underlies boundary sharpening and maintenance is mediated by cortical tension. Signaling from one cell population (red) induces assembly and contraction of cell-surface-associated actomyosin in the adjacent cells (blue). This cortical tension sharpens the borders and restrains movement of cells across the interface.

6 in segregation across the border of the lateral ganglionic eminence and cerebral cortex in the mouse forebrain (Inoue et al. 2001). Similarly, DE-cadherin is required for correct localization of the oocyte in Drosophila follicles (Godt and Tepass 1998), and MN-cadherin for segregation of motor neuron subtypes in the chick spinal cord (Price et al. 2002).

Studies of several protocadherins with tissue-restricted expression have revealed that these too can mediate cell segregation and contribute to border formation; for example, paraxial protocadherin (PAPC) drives segregation when ectopically expressed and is required to form epithelial boundaries during somitogenesis (Kim et al. 1998, 2000; Rhee et al. 2003). However, structural studies and binding assays suggest that protocadherins do not mediate homophilic cell adhesion (Morishita and Yagi 2007). Rather, PAPC binds C-cadherin and decreases its adhesive activity (Chen and Gumbiner 2006), whereas interactions between protocadherin-19 and N-cadherin increase adhesive activity (Biswas et al. 2010). These findings raise the prospect of wider roles of protocadherins in cell segregation and boundary formation through the modulation of cadherin activity.

\subsection{Evidence that Other Mechanisms Contribute to Cell Segregation}

Although the results of reaggregation assays show that differential adhesion can drive cell segregation, several exceptions have been found to the prediction that the more cohesive population will segregate to the inside of a reaggregate. One example comes from studies revealing roles of cortical tension in cell segregation (Krieg et al. 2008), discussed below. Another example has been found in reaggregation assays with amphibian embryo tissues: When mesoderm or endoderm cells are reaggregated with epithelial ectoderm cells, the latter, more cohesive, population segregates to the outside rather than the inside (Townes and Holtfreter 1955). Similar results have been found with mouse embryonic stem cells and primitive endoderm, in which the latter cells form an outer epithelium (Moore et al. 2009). A likely explanation is that the epithelial cells are intrinsically polarized, with a nonadhesive apical surface that stabilizes the assembly of the epithelium at the outer surface. Importantly, it has been found that adhesive interactions of other cells with the epithelial layer can re- 
verse the relative positioning of cell types in reaggregates, such that they acquire the normal configuration seen in the developing embryo (Krieg et al. 2008; Ninomiya and Winklbauer 2008).

A further important consideration is whether differential adhesion is sufficient to generate a sharp interface between cell populations. Unlike oil and water, cells have free energy that underlies their active migration and is capable of overwhelming adhesion-driven forces (Harris 1976). Such intrinsic motility on the one hand enables the movement of cells so that they can meet new neighbors, but on the other hand can destabilize tissue organization. The borders formed after differential adhesion-driven cell segregation in vitro do not match the sharp interfaces of boundaries in vivo, and it therefore seems likely that additional, or alternative, mechanisms contribute to the sharpening of borders.

\subsection{Other Potential Roles of Restricted Cadherin Expression during Development}

Despite the striking differential expression of specific cadherins across many tissue borders, there is a paucity of evidence from loss-of-function manipulations for a role in the restriction of cell intermingling (Winklbauer 2009). One possible explanation is that there is overlapping expression and functional redundancy between cadherin family members, but at some borders this may instead reflect the existence of other cell segregation mechanisms. An example is the notochord-somite border, where expression of a dominant negative cadherin has no effect on cell segregation, arguing that cadherin-independent mechanisms are sufficient (Reintsch et al. 2005). This raises the question of whether tissue- or region-specific cadherin expression in some cases reflects roles other than in cell segregation. Indeed, cadherins are essential for many other aspects of tissue morphogenesis, such as formation of epithelia, modulation of cell shape, and cell migration (Halbleib and Nelson 2006; Lecuit and Lenne 2007). One example is the switch in cadherin expression in the transition from epithelial to mesenchymal cells that enables the more dynamic adhesion required for migratory behavior (Takeichi et al. 2000; Coles et al. 2007; Park and Gumbiner 2010), and promotes motility of tumor cells (Nieman et al. 1999; Hazan et al. 2000). Another example comes from studies of roles of cadherins in collective cell migration, discussed below.

\section{REGULATION OF CELL MIGRATION BY CADHERINS}

In the differential adhesion hypothesis, it is proposed that there is no directed migration of cells, but rather cell motility enables reorganization of the distinct cell populations to achieve the lowest free energy of the adhesive interactions. An alternative to this facilitative role of cell migration was proposed by Abercrombie based on time lapse analyses of cell interactions in culture (Abercrombie 1979). These studies revealed that collisions between cells can trigger contact inhibition, in which there is a collapse of the leading lamellipodia and consequent arrest of cell migration, which may subsequently be reinitiated in a new direction (Abercrombie and Heaysman 1953). Contact inhibition on interaction of cells from adjacent tissues would prevent one population from migrating into the other, and loss of this mechanism could thus underlie the invasive behavior of metastatic tumor cells (Abercrombie 1979).

A number of findings suggest that cadherin-mediated interactions can regulate cell migration directly, rather than only via the generation of mechanical forces. For example, the asymmetry in cadherin-mediated interactions of cells at the edge of a tissue sheet leads to cell polarization such that migration occurs away from the cell contacts (Desai et al. 2009; Dupin et al. 2009). Furthermore, N-cadherin can mediate the contact inhibition of cell migration (Theveneau et al. 2010). However, because cadherin-mediated interactions are preferentially homophilic, this does not provide a mechanism to restrict intermingling between cell populations. In order for contact inhibition to restrict cell intermingling, it needs to be triggered by heterotypic interactions between distinct cell types, and such a mechanism has been uncovered in studies of Eph receptors and ephrins, discussed below.

Although contact inhibition appears unlikely to be a mechanism by which cadherins drive cell segregation, it may contribute in other ways to the stabilization of tissue organization. A striking illustration of this is the role of cadherin-mediated polarization in the migration of neural crest cells in Xenopus embryos (Theveneau et al. 2010). In this system, neural crest cells migrate chemotactically toward higher levels of the chemokine, Sdf1, but in the absence of cell contacts the direction of migration shows only a weak bias toward the source of attractant. However, in vivo, neural crest cells migrate as a sheet of dynamically interacting cells, within which $\mathrm{N}$-cadherin-mediated contacts inhibit Rac1 activation and thus suppress lamellipodia formation. As a consequence, lamellipodia formation in response to chemoattractant is preferentially maintained at the free edge of cells at the front of the sheet, conferring a high directionality to cell migration. In addition, cadherin-mediated interactions promote the coherence of migration, such that adjacent cells tend to remain together (Borghi et al. 2010; Theveneau et al. 2010). It can be envisaged that both adhesive interactions and contact inhibition contribute to this stabilization of cell organization by promoting the directionality of migration and restraining the intermingling of cells. 
Another perspective on roles of adhesion in cell migration comes from studies of convergent-extension movements during gastrulation in which lateral cells migrate toward the midline of the embryo. It has been shown that directed migration requires a bone morphogenetic protein (BMP) gradient that establishes a reverse gradient of cell adhesiveness (von der Hardt et al. 2007). Furthermore, cell migration is oriented if a gradient of calcium-dependent cell adhesion is artificially created by use of a calcium chelator. It is proposed that cell migration is oriented owing to preferential stabilization of contacts between lamellipodia and the more adhesive neighbors, such that the cell is displaced toward the latter on retraction of the lamellipodia (von der Hardt et al. 2007). A role of cadherins in directional migration has also been uncovered for cerebellar granule neurons that migrate as chains of cells. Time lapse imaging reveals a dynamic regulation of cell polarity in which cadherin-2 protein shifts along the cell membrane to the front of the cell, and this may orient migration by stabilizing the centrosome at the leading edge (Rieger et al. 2009). The modulation of directional migration by cadherins also involves interactions with integrin-mediated adhesion to extracellular matrix (Borghi et al. 2010). Indeed, more broadly the signaling and adhesive activities of integrins and cadherins form components of an integrated network (Weber et al. 2011). These findings that cadherins can regulate the internal polarity of cells and coordinate their directional migration challenge the assumption that cadherins drive segregation only via mechanical forces acting on randomly motile cells.

\section{ROLES OF CELL CORTEX TENSION}

The differential adhesion hypothesis proposes that interfacial tension between tissues that maintains segregation derives solely from the relative amounts of adhesiveness of distinct cell populations (Foty and Steinberg 2005). However, an alternative view is that segregation can be driven by tension and cell-surface contraction generated independently of differential adhesion (Harris 1976). There is now good evidence that tension generated by the contraction of actomyosin in the cell cortex has important roles in the segregation of specific cell populations (Lecuit and Lenne 2007; Paluch and Heisenberg 2009). An elegant study of zebrafish embryo germ layers (Krieg et al. 2008) found that mesoendoderm cells are more cohesive than ectoderm cells, which would be predicted to generate greater surface tension of mesoendoderm and consequently, their segregation to the inside of reaggregates. However, mesoendoderm cells actually segregate to the outside of ectoderm cells in reaggregates. This pattern of segregation can be explained by the finding that ectoderm cells have a higher actomyosin-dependent cell cortex tension, which is regulated by Nodal signaling. In support of this, inhibition of actomyosin activity, such that cell cortex tension is decreased in ectoderm cells, causes them to instead segregate to the outside of reaggregates (Krieg et al. 2008).

Evidence for a role of cell cortex tension in boundary formation has come from studies in Drosophila. Initial clues came from the findings that in the wing imaginal disc there is an increased amount of actin and myosin II protein at the dorsal-ventral (Major and Irvine 2005, 2006) and anteriorposterior compartment boundaries (Landsberg et al. 2009) compared with nonboundary regions. Because myosin II function is essential for the sharpness of these borders (Major and Irvine 2006; Landsberg et al. 2009), this suggests a model in which actomyosin contraction generates cell cortex tension. Indeed, the measurement of tension by laser cutting of cell bonds has shown that there is $\sim 2.5$-foldhigher tension along the anterior-posterior compartment boundary compared with nonboundary regions, which computer simulations suggest is sufficient to generate cell segregation (Landsberg et al. 2009). A recent study has revealed an analogous role of myosin II in restricting cell mixing across the parasegmental boundaries of the Drosophila embryo (Monier et al. 2010). The sharpness of the parasegment borders is challenged by movements occurring on cell division, but any cells that move toward the adjacent compartment rapidly relocate back to their origin. However, this restriction to cell movement no longer occurs if the myosin II cable at the compartment border is disrupted by laser-mediated inactivation (Monier et al. 2010). These findings suggest that actomyosin-mediated tension creates a fence at the boundary that prevents the crossing of cells between compartments.

The mechanisms that underlie myosin II accumulation and actomyosin contraction are currently unclear, but are known to lie downstream from signals that have critical roles in formation of compartment boundaries (Irvine and Rauskolb 2001): wingless signaling at parasegmental boundaries (Monier et al. 2010) and Notch activation at the wing disc dorsal-ventral boundary (Major and Irvine 2005). Thus, as for zebrafish germ layers (Krieg et al. 2008), this suggests a model in which segregation and boundary sharpening is established by intercellular signaling that leads to actomyosin contraction and increased cell cortex tension (Fig. 2B).

\section{CELL SEGREGATION BY EPH-EPHRIN SIGNALING}

A further mechanism that underlies cell segregation across specific boundaries has been identified through studies of Eph receptor tyrosine kinases and their ephrin ligands. In 
vertebrates, Eph receptors comprise a large family of proteins, subdivided into EphA and EphB subclasses based on their sequence similarities and binding to ephrins (Gale et al. 1996). With some exceptions, EphA receptors bind to the glycosylphosphatidylinositol (GPI) -anchored ephrinAs, whereas EphB receptors bind to the transmembrane ephrinBs, and because both components are membranebound the interactions require cell-to-cell contact. Remarkably, the binding and clustering of Eph receptors and ephrins can lead to signal transduction through both components, thus eliciting bidirectional signaling (Holland et al. 1996; Bruckner et al. 1997). Signaling through Eph receptors and ephrins is highly complex and acts through multiple pathways (Jorgensen et al. 2009) to affect cell phenotype, including the regulation of cell migration, proliferation, and differentiation (Kullander and Klein 2002; Poliakov et al. 2004; Pasquale 2005; Bush and Soriano 2010). Of potential relevance to roles in cell segregation, Eph-ephrin interactions can control polymerization of the actin cytoskeleton, cadherin function, and integrin-mediated adhesion.

Initial evidence for roles of Eph-ephrin signaling in boundary formation came from studies of the segmentation of the vertebrate hindbrain to form rhombomeres. Cell intermingling is restricted across rhombomere boundaries (Fraser et al. 1990) owing to distinct cellular properties of odd- versus even-numbered segments (Guthrie et al. 1993). This correlates with the expression of EphA4 and specific EphB receptors in rhombomeres $r 3$ and $r 5$, whereas corresponding ephrinB ligands are expressed in $\mathrm{r} 2, \mathrm{r} 4$, and r6 (Nieto et al. 1992; Becker et al. 1994; Bergemann et al. 1995; Flenniken et al. 1996; Chan et al. 2001). The results of blocking Eph receptor activation, and of injecting Eph receptor or ephrinB RNA to create embryos with mosaic overexpression revealed that Eph-ephrin interactions underlie cell segregation across hindbrain boundaries (Xu et al. 1995, 1999). This may reflect a general role because cell culture assays have shown that complementary expression of Eph receptor and ephrinB genes is sufficient to maintain sharp borders (Mellitzer et al. 1999) and to segregate intermingled cells (Tanaka et al. 2003; Cortina et al. 2007; Poliakov et al. 2008). Indeed, reciprocal expression of Eph receptors and ephrins occurs in many tissues during development (Gale et al. 1996), and has been implicated in boundary formation during somitogenesis (Barrios et al. 2003; Julich et al. 2009) and cell segregation in limbs (Compagni et al. 2003; Davy et al. 2004). An interesting example is the role of counter gradients of EphB and ephrinB expression in maintaining the segregation of progenitors and differentiating cells in intestinal crypts (Batlle et al. 2002), which are relevant to mechanisms of tumor metastasis (Batlle et al. 2005), discussed below. These studies raise the question of the mechanisms by which Eph receptor and ephrin-expressing cells segregate.

\subsection{Eph-Ephrin Signaling and Differential Adhesion}

One potential mechanism by which Eph-ephrin signaling may drive segregation is that cell repulsion creates differential adhesion (Steinberg 2007). Indeed, E-cadherin-mediated adhesion contributes to Eph-ephrin-mediated cell segregation, and EphB activation regulates the subcellular localization of E-cadherin (Cortina et al. 2007). Direct support for regulation of differential adhesion comes from recent studies revealing a mechanism by which Eph-ephrin interactions lead to decreased cadherin-mediated adhesion. Previous studies showed that EphA3 interacts with the metalloproteinase ADAM10, and that on binding to ephrinA ligand and receptor activation, ADAM10 cleaves ephrinA protein thus enabling cell disengagement (Hattori et al. 2000; Janes et al. 2005). It has recently been shown that recruitment of ADAM10 also occurs on interaction of EphB3 and ephrinB1, and that in epithelial tissues EphB receptors interact with E-cadherin, which is a substrate for ADAM10 (Solanas et al. 2011). Consequently, EphB3-ephrinB1 binding triggers cleavage and shedding of E-cadherin at the interface of their interactions, thus establishing differential adhesion that contributes to cell segregation in vitro (Solanas et al. 2011). Moreover, inhibition of ADAM10 in the intestine disrupts the organization of the stem cell niche that is regulated by EphB3 signaling (Solanas et al.2011). A further mechanism by which Eph-ephrin signaling may decrease cell adhesion is by inhibiting the function of connexins, which contribute to adhesive interactions as well as mediating gap junctional communication (Mellitzer et al. 1999; Davy et al. 2006).

Further insights into roles of Eph-ephrin signaling come from experiments in which cell transplantation is performed to create mosaic embryos in which EphA4 or ephrinB2 has been knocked down in a subset of cells. It was found that the "knockdown" cells segregate to the borders of the hindbrain segments that normally express EphA4 or ephrinB2, respectively (Cooke et al. 2005; Kemp et al. 2009). These results show that Eph receptors and ephrins are not solely acting at borders to restrict intermingling, but it is currently unclear what type of cell response drives segregation within hindbrain segments. One possibility is suggested by the findings that in some contexts, rather than causing cell repulsion, Eph-ephrin signaling can promote the adhesion of cells, required, for example, for fusion of specific epithelial sheets (Holmberg et al. 2000; Dravis et al. 2004). The basis of an adhesive rather than repulsive cell response is unclear, but may reflect that Eph-ephrin 
signaling activates some pathways that promote adhesion (Lee et al. 2008), whereas high levels of activation of other pathways trigger cell repulsion (Holmberg et al. 2000; Hansen et al. 2004). One way in which low-level activation may be achieved is through cis-inhibitory interactions of coexpressed Eph receptors and ephrins (Hornberger et al. 1999; Yin et al. 2004; Carvalho et al. 2006), and it is likely that overlapping expression occurs in many tissues (Sobieszczuk and Wilkinson 1999). Alternatively, adhesion may be increased by overlapping expression of Eph receptor and ephrinB because this coactivates specific pathways within the same cells (Dravis et al. 2004). Taken together, these findings suggest a model in which Eph-ephrin signaling restricts cell intermingling by increasing adhesion within specific territories and by decreasing adhesion across borders.

\subsection{Eph-Ephrin Signaling and Cell Migration}

Studies of roles in axon guidance and cell migration have shown that Eph receptor and ephrin signaling can mediate contact-dependent repulsion that prevents entry into inappropriate territory (Poliakov et al. 2004; Pasquale 2005; Egea and Klein 2007). In cell segregation assays, this is seen at the single cell level to involve cytoskeletal collapse of cell processes following the interaction between Eph receptor and ephrinB-expressing cells (Poliakov et al. 2008). Although the interaction of Eph receptors with ephrins initially mediates strong binding between cells, the interaction activates proteolytic cleavage and/or endocytosis of Eph/ephrin complexes that then enables Eph- and ephrin-expressing cells to disengage (Hattori et al. 2000; Marston et al. 2003; Zimmer et al. 2003). These findings suggest that complementary expression of Eph receptors and ephrins may restrict cell intermingling across borders by bidirectional repulsion of the two cell populations (Mellitzer et al. 1999). This model is similar to the proposal of Abercrombie that invasion of tumor cells is restricted by the contact inhibition of cell migration (Abercrombie 1979), and indeed recent work has implicated Eph-ephrin signaling in contact inhibition of tumor cell lines (Astin et al. 2010).

Studies of border formation between ectoderm and mesoderm during Xenopus gastrulation have provided important insights into how Eph-ephrin signaling underlies the restriction of cell intermingling (Rohani et al. 2011). In this system, mesodermal cells migrate on the ectoderm of the blastocoel roof, while not migrating into the ectodermal tissue. This behavior involves repeated cycles of adhesive interactions and retraction of the mesoderm cells at the border, such that the ectoderm provides a substrate for migration, while repelling the mesodermal cells from invading the ectoderm. The formation of the border requires signal- ing through EphB receptors to activate Rac and RhoA both in mesoderm and ectoderm cells; this bidirectional forward signaling is established by the overlapping expression of distinct EphB receptors and ephrinBs in each of the adjacent cell populations. Importantly, although Eph-ephrin signaling increases cell adhesion in ectoderm, but not mesoderm, this is not required for the tissue separation behavior at the border (Rohani et al. 2011).

Taken together, these studies suggest that Eph-ephrin interactions may drive cell segregation through multiple mechanisms: by triggering de-adhesion that generates differential adhesion between Eph receptor and ephrin-expressing cells; by creating global differences in cell adhesion; and by contact repulsion that restricts cell migration (Fig. 3). The relative contribution of these mechanisms to boundary formation is currently unclear, and may be dependent on context, such as the migratory and adhesive properties of the interacting cell populations.

\subsection{Integrin Activation at Somite Borders}

Insights into a further mechanism by which Eph-ephrin signaling underlies boundary formation have been uncovered in studies of somitogenesis. Interactions between EphA4 and ephrinB2 at the borders of complementary domains in presomitic mesoderm has a crucial role in boundary formation by inducing the mesenchymal cells to form the polarized epithelium of the somites (Barrios et al. 2003). At later stages, there is an integrin $\alpha 5$-dependent accumulation of fibronectin matrix at somite borders that is required for continued stabilization of the boundary (Julich et al. 2005; Koshida et al. 2005). This accumulation of extracellular matrix is attributable to ephrin activation that underlies an "inside-out" increase in the affinity of integrin $\alpha 5$ for its ligands (Julich et al. 2009). These findings suggest a sequential process in which Eph-ephrin interactions both initiate boundary formation and induce the accumulation of fibronectin, which in turn maintains the boundary by activation of integrin signaling.

\section{CELL ADHESION AND TISSUE BOUNDARIES AS SUPPRESSORS OF TUMOR PROGRESSION}

Many of the same mechanisms underlying cell segregation during development also act to constrain tumor growth and prevent the dissemination of cancer cells, which frequently retain the expression of cell adhesion and cell repulsion molecules characteristic of the tissue from which they originated. Thus there is much interest in uncovering the contributions of cell adhesion and repulsion to tumor formation and progression. 
A

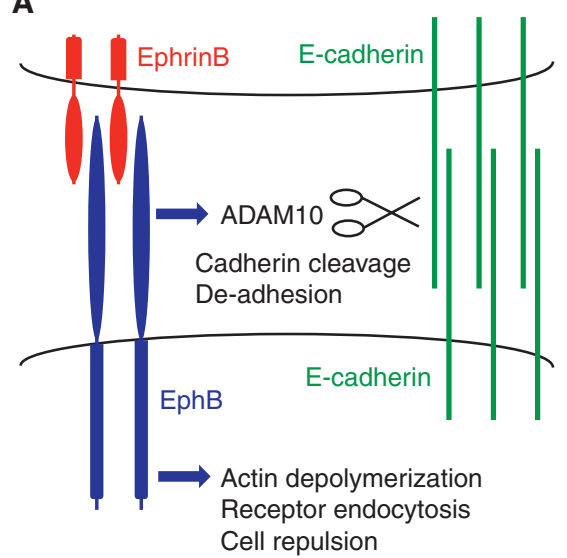

B

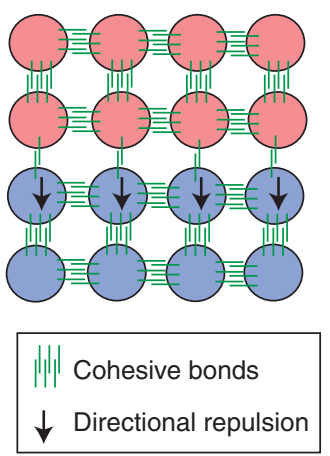

Figure 3. Eph receptor and ephrin signaling. (A) Interactions between EphB receptor and ephrinB ligand can trigger two mechanisms that underlie cell segregation. The first is mediated by interactions of EphB receptor with the metalloproteinase ADAM10 and with E-cadherin. On binding of EphB receptor to ephrinB ligand, ADAM10 activity cleaves E-cadherin, thus leading to decreased adhesion selectively at the Eph-ephrin interface. The second mechanism involves signaling pathways downstream from activated EphB receptor that lead to depolymerization of the actin cytoskeleton, with concommitant endocytosis of Eph-ephrin complexes. The combination of cytoskeletal collapse and cell disengagement leads to repulsion of EphB- by ephrinB-expressing cells. $(B)$ Decreased E-cadherinmediated adhesion between EphB and ephrinB cells establishes differential adhesion. Directional repulsion of EphB-expressing cells by ephrinB-expressing cells prevents intermingling. These two mechanisms may act together to establish and maintain cell segregation.

\subsection{Cell Adhesion in Tumor Progression: Cadherins Control Tumor Cell Dissemination and Epithelial-to-Mesenchymal Transition}

Amongst all adhesion molecules, E-cadherin acts as the central suppressor of cancer dissemination in tumors of epithelial origin. Loss of E-cadherin-mediated adhesion correlates with an invasive phenotype and poor prognosis in several tumor types (van Roy and Berx 2008; Makrilia et al. 2009). Several mechanisms can underlie diminished E-cadherin-based adhesion in epithelial tumor cells. A small subset of tumors acquires inactivating mutations in the E-cadherin gene $(\mathrm{CDH} 1)$. These alterations are more prevalent in diffuse gastric (Berx et al. 1998a,b; Machado et al. 2001) and infiltrating lobular breast cancers (Berx et al. 1996, 1998a). Epigenetic silencing of the CDH1 locus is also a common finding in epithelial cancers (Machado et al. 2001; van Roy and Berx 2008). The assembly and stability of adherens junction components can be reduced in tumor cells through posttranscriptional modification of its components. A prime example is phosphorylation of the intracellular domain of E-cadherin by receptor tyrosine kinases such as c-met, or by src, which induces internalization and degradation of E-cadherin via the interaction with the E3-ubiquitin ligase Hakai (Fujita et al. 2002). Disruption of adherens junctions can also be mediated by tyrosine phosphorylation of specific residues of $\beta$-catenin that decrease its affinity for E-cadherin (Roura et al. 1999). Given that hyperactivation of tyrosine kinases is a prevalent alteration in cancer, these mechanisms may account for cancer dissemination in many tumor types.

Transcriptional regulators of epithelial-to-mesenchymal transition (EMT) during development are frequently expressed by tumor cells, inducing mesenchymal-like phenotypes that lead to transcriptional silencing of E-cadherin (Thiery et al. 2009). Some key regulators of EMT such as Snail1, Snail2, Zeb1, Zeb2, or E47 are transcriptional repressors that silence the expression of E-cadherin by direct binding to its promoter (Thiery et al. 2009). Other regulators of EMT (e.g., the transcriptional activator Twist) promote mesenchymal phenotypes without repressing Ecadherin directly (Thiery et al. 2009). EMT involves not only silencing of E-cadherin expression but also coordinated changes that confer a migratory phenotype to tumor cells. These include loss of cell polarity, activation of metalloproteinase activity, as well as global changes in the cell cytoskeleton (Thiery et al. 2009). An important phenomenon in EMT is cadherin switching, such as the expression of mesenchymal $\mathrm{N}$-cadherin on silencing of E-cadherin in tumor cells. The different properties of $\mathrm{N}$-cadherin and $\mathrm{E}$ cadherin have been analyzed by engineering knockin mice conditionally expressing $\mathrm{N}$-cadherin from the E-cadherin locus (Libusova et al. 2010). Mice with E-cadherin substituted by $\mathrm{N}$-cadherin in intestinal epithelial cells displayed normal intestinal development suggesting no major defects in cell adhesion (Libusova et al. 2010). Yet, as these mice 
aged, they developed crypt dysplasia as a result of enhanced Wnt signaling owing to increased nuclear localization of $\beta$-catenin (Libusova et al. 2010). This phenotype may be explained by the inability of $\mathrm{N}$-cadherin to quench $\beta$-catenin, perhaps as a result of E-cadherin and $\mathrm{N}$-cadherin showing different affinities for $\beta$-catenin. Additional studies have also revealed that expression of $\mathrm{N}$-cadherin readily confers migratory properties to tumor cells (Nieman et al. 1999; Hazan et al. 2000). This is in part owing to the establishment of homotypic adhesions between $\mathrm{N}$ cadherin-expressing tumor cells and stromal cells during invasion (Hazan et al. 1997; Tran et al. 1999). The effects of $\mathrm{N}$-cadherin as a promoter of cell motility have also been connected to its specific interaction with fibroblast growth factor (FGF) receptor (Hazan et al. 2000; Williams et al. 2001; Suyama et al. 2002). N-Cadherin prevents ligand-induced internalization of FGF receptor, causing sustained downstream signaling, which results in an enhanced invasive phenotype (Suyama et al. 2002).

\subsection{EphB-EphrinB Signaling in Colorectal Cancer: Eph-Ephrin Signaling Imposes Boundary Formation in Solid Tumors}

There is emerging evidence that boundary formation imposed by Eph-ephrin interactions can also restrict the progression of cancer. Perhaps the best understood example is the role of EphB signaling in colorectal cancer (CRC). Most CRCs are initiated as benign tumors called adenomas, which arise on mutational activation of the canonical Wnt signaling pathway (Clevers 2006). EphB2 and EphB3 are direct target genes of $\beta$-catenin/Tcf, the transcriptional effector complex of the Wnt pathway (Batlle et al. 2002; Hatzis et al. 2008). As a consequence, intestinal adenomas express high levels of EphB2 and EphB3 (Batlle et al. 2002, 2005). In contrast, in the most aggressive CRCs the expression of EphB2 and EphB3 is silenced despite constitutive activation of the Wnt signaling pathway (Batlle et al. 2005). Silencing of EphB2 correlates with poor prognosis in CRC (Jubb et al. 2005; Guo et al. 2006). The effects of EphB silencing on tumor progression have been studied in ApcMin/ + mice, a mouse model of intestinal tumorigenesis. ApcMin/+ mice spontaneously develop adenomas in the intestine, which remain largely benign. In ApcMin/+ mice bearing EphB3 or ephrinB1 loss-of-function alleles, colon adenomas rapidly progressed to invasive cancers, implying a causal role for EphB silencing in CRC progression (Batlle et al. 2005; Cortina et al. 2007). In vitro and in vivo evidence suggests that $\mathrm{EphB}$ receptors suppress CRC progression by mediating the restriction of migration of tumor cells into ephrinB1-expressing territory. Activation of EphB activity in fully malignant CRC cells enforces compartmentalized growth as opposed to a disseminated distribution (Cortina et al. 2007). This phenomenon depends on the ability of EphB signaling to enforce cell sorting and E-cadherin-mediated adhesion in cultured CRC cell lines (Cortina et al. 2007). Analysis of tumor formation in ApcMin/+ mice confirmed that the expression of EphB receptors in tumor cells prevented their spreading into the adjacent normal epithelium, which have high levels of ephrinB1 expression (Cortina et al. 2007). Interestingly, expression of EphB3 reverts EMT in CRC cell lines (Chiu et al. 2009). This observation fits well with the silencing of EphB receptors observed at invasion fronts and in poorly differentiated tumors (Batlle et al. 2005; Jubb et al. 2005; Guo et al. 2006), and suggests that decreased EphB signaling plays a role during metastatic dissemination.

\subsection{EphB4 Signaling in Breast Cancer: Tumor Suppression Activity Is Mediated by Eph Signaling}

In breast cancer, EphB4 signaling has been shown to act as both a tumor suppressor or promoter depending on the experimental context (reviewed by Noren and Pasquale 2007). Blockade of constitutive EphB4 signaling present in nontransformed breast cell lines diminishes cell-to-cell adhesion and promotes a mesenchymal-like phenotype (Noren et al. 2006), similar to the effects induced by EphB signaling in CRC cell lines (Cortina et al. 2007; Chiu et al. 2009). In vivo, activation of EphB4 inhibits breast cancer growth in xenograft models (Noren et al. 2006). This tumor suppressor mechanism depends on the activation of the kinase Abl by EphB4, which in turn phosphorylates and blocks the activity of the adaptor protein Crk (Noren et al. 2006). In addition, the EphB4-AblCrk axis negatively controls the expression of the metalloproteinase MMP2, which may account for the reduced invasion capacity of breast cancer cells on activation of EphB4 (Noren et al. 2006). Paradoxically, overexpression of EphB4 in transgenic mouse synergizes with Neu oncogene in the formation of mammary tumors (Munarini et al. 2002). Independent studies have also shown that EphB4 exerts prosurvival signals in breast cancer cell lines (Kumar et al. 2006). In the same study, tumors derived from breast cancer cell lines engineered to express low levels of EphB4 displayed defects in vascularization (Kumar et al. 2006). Indeed, anti-EphB4 monoclonal antibodies block vasculogenesis in xenograft models derived from several cancer cell lines, including breast cancer (Krasnoperov et al. 2010). This observation implies that protumorigenic effects of EphB4 occur in part through a tumor cell nonautonomous mechanism, in which ephrin-B2 is activated in vascular endothelial cells. 
6.4 Eph-Ephrin Signaling in Prostate Cancer: Eph-Ephrin Signals Influence Tumor Cell Migration

The migratory behavior of prostate cancer cells is also largely controlled by Eph-ephrin interactions. Dissemination of tumor cells occurs through the invasion of the surrounding stroma, in which the most abundant cells are tumor-associated fibroblasts (TAFs). In vitro cocultures of metastatic prostate cells with TAFs highlighted opposing roles for EphB-ephrinB and EphA-ephrinA interactions in the regulation of tumor cell migration (Astin et al. 2010). Activation of EphB3 or EphB4 in prostate cancer cells by ephrinB2 expressed in fibroblasts promotes migration via cdc42 activation and enhancement of filopodia formation. In contrast, interaction of EphA2 and EphA4 receptors with ephrinA ligands present at the surface of neighboring prostate tumor cells induces contact inhibition of locomotion by triggering Rho-mediated contractility (Astin et al. 2010). Thus, EphA and EphB receptors have antagonizing functions during the dissemination of prostate cancer cells. These results also imply that the recruitment of ephrinB2 ${ }^{+}$ fibroblasts to the tumor microenvironment would promote tumor cell migration by favoring EphB over EphA signaling.

\section{CONCLUDING REMARKS}

There has been significant progress in uncovering mechanisms that underlie the segregation of cell populations and formation of boundaries. Furthermore, several of the mechanisms found to act in development also maintain tissue organization in the adult, and when defective contribute to metastasis during tumor progression. One type of mechanism is mediated by intrinsic global differences in adhesiveness between cell populations that can drive segregation and establish interfacial tension across borders. More recently, other mechanisms have been uncovered that involve local signaling between cells: the induction of cortical tension at specific boundaries, and bidirectional activation of Eph receptors and ephrins that regulates cell migration and adhesion. The findings that differential adhesion, cortical tension, and Eph signaling can each mediate cell segregation suggest that they can act as alternative mechanisms that have been recruited to serve at distinct boundaries, or at different stages of boundary formation and maintenance (Milan et al. 2001; Major and Irvine 2005). However, it remains to be addressed whether individually these mechanisms account for the rate and extent of segregation that occurs following mixing of distinct cell populations, or for the remarkable sharpness of borders between tissues or tissue subdivisions; for example, mathematical modeling of cortical tension does not fully account for border sharpness (Landsberg et al. 2009). It will therefore be important to determine whether multiple mechanisms are required to achieve cell segregation, for example, acting additively, or synergistically through an interplay between biochemical pathways, such as the feedback between adhesion and cortical tension (Monier et al. 2011).

\section{ACKNOWLEDGMENTS}

Eduard Batlle was supported by grants from the European Research Council (ERC) and the Spanish Ministry of Science and Innovation (SAF and Consolider), and David Wilkinson by the Medical Research Council (U117532048).

\section{REFERENCES}

Abercrombie M. 1979. Contact inhibition and malignancy. Nature 281: $259-262$.

Abercrombie M, Heaysman JE. 1953. Observations on the social behaviour of cells in tissue culture. I. Speed of movement of chick heart fibroblasts in relation to their mutual contacts. Exp Cell Res 5: 111-131.

Astin JW, Batson J, Kadir S, Charlet J, Persad RA, Gillatt D, Oxley JD, Nobes CD. 2010. Competition amongst Eph receptors regulates contact inhibition of locomotion and invasiveness in prostate cancer cells. Nat Cell Biol 12: 1194-1204.

Barrios A, Poole RJ, Durbin L, Brennan C, Holder N, Wilson SW. 2003. Eph/ephrin signaling regulates the mesenchymal-to-epithelial transition of the paraxial mesoderm during somite morphogenesis. Curr Biol 13: $1571-1582$.

Batlle E, Henderson JT, Beghtel H, van den Born MM, Sancho E, Huls G, Meeldijk J, Robertson J, van de Wetering M, Pawson T, et al. 2002. $\beta$-catenin and TCF mediate cell positioning in the intestinal epithelium by controlling the expression of EphB/ephrinB. Cell 111: 251263.

Batlle E, Bacani J, Begthel H, Jonkeer S, Gregorieff A, van de Born M, Malats N, Sancho E, Boon E, Pawson T, et al. 2005. EphB receptor activity suppresses colorectal cancer progression. Nature 435: $1126-$ 1130.

Becker N, Seitanidou T, Murphy P, Mattei MG, Topilko P, Nieto MA, Wilkinson DG, Charnay P, Gilardi-Hebenstreit P. 1994. Several receptor tyrosine kinase genes of the Eph family are segmentally expressed in the developing hindbrain. Mech Dev 47: 3-17.

Bergemann AD, Cheng HJ, Brambilla R, Klein R, Flanagan JG. 1995. ELF-2, a new member of the Eph ligand family, is segmentally expressed in mouse embryos in the region of the hindbrain and newly forming somites. Mol Cell Biol 15: 4921-4929.

Berx G, Cleton-Jansen AM, Strumane K, de Leeuw WJ, Nollet F, van Roy F, Cornelisse C. 1996. E-cadherin is inactivated in a majority of invasive human lobular breast cancers by truncation mutations throughout its extracellular domain. Oncogene 13: 1919-1925.

Berx G, Becker KF, Hofler H, van Roy F. 1998a. Mutations of the human E-cadherin (CDH1) gene. Hum Mutat 12: 226-237.

Berx G, Nollet F, van Roy F. 1998b. Dysregulation of the E-cadherin/catenin complex by irreversible mutations in human carcinomas. Cell Adhes Commun 6: 171-184.

Biswas S, Emond MR, Jontes JD. 2010. Protocadherin-19 and Ncadherin interact to control cell movements during anterior neurulation. J Cell Biol 191: 1029-1041.

Borghi N, Lowndes M, Maruthamuthu V, Gardel ML, Nelson WJ. 2010. Regulation of cell motile behavior by crosstalk between cadherin- and integrin-mediated adhesions. Proc Natl Acad Sci 107: 13324-13329. 
Bruckner K, Pasquale EB, Klein R. 1997. Tyrosine phosphorylation of transmembrane ligands for Eph receptors. Science 275: 1640-1643.

Bush JO, Soriano P. 2010. Ephrin-B1 forward signaling regulates craniofacial morphogenesis by controlling cell proliferation across Eph-ephrin boundaries. Genes Dev 24: 2068-2080.

Carvalho RF, Beutler M, Marler KJ, Knoll B, Becker-Barroso E, Heintzmann R, Ng T, Drescher U. 2006. Silencing of EphA3 through a cis interaction with ephrinA5. Nat Neurosci 9: 322-330.

Chan J, Mably JD, Serluca FC, Chen JN, Goldstein NB, Thomas MC, Cleary JA, Brennan C, Fishman MC, Roberts TM. 2001. Morphogenesis of prechordal plate and notochord requires intact Eph/ephrin B signaling. Dev Biol 234: 470-482.

Chen X, Gumbiner BM. 2006. Paraxial protocadherin mediates cell sorting and tissue morphogenesis by regulating C-cadherin adhesion activity. J Cell Biol 174: 301-313.

Chiu ST, Chang KJ, Ting CH, Shen HC, Li H, Hsieh FJ. 2009. Overexpression of EphB3 enhances cell-cell contacts and suppresses tumor growth in HT-29 human colon cancer cells. Carcinogenesis 30: $1475-1486$.

Clevers H. 2006. Wnt/ $\beta$-catenin signaling in development and disease. Cell 127: 469-480.

Coles EG, Taneyhill LA, Bronner-Fraser M. 2007. A critical role for Cadherin6B in regulating avian neural crest emigration. Dev Biol 312: $533-544$.

Compagni A, Logan M, Klein R, Adams RH. 2003. Control of skeletal patterning by ephrinB1-EphB interactions. Dev Cell 5: 217-230.

Cooke JE, Kemp HA, Moens CB. 2005. EphA4 is required for cell adhesion and rhombomere-boundary formation in the zebrafish. Curr Biol 15: $536-542$.

Cortina C, Palomo-Ponce S, Iglesias M, Fernandez-Masip JL, Vivancos A, Whissell G, Huma M, Peiro N, Gallego L, Jonkheer S, et al. 2007. EphB ephrin-B interactions suppress colorectal cancer progression by compartmentalizing tumor cells. Nat Genet 39: 1376-1383.

Dahmann C, Basler K. 1999. Compartment boundaries: At the edge of development. Trends Genet 15: 320-326.

Dahmann C, Oates AC, Brand M. 2011. Boundary formation and maintenance in tissue development. Nat Rev Genet 12: 43-55.

Davy A, Aubin J, Soriano P. 2004. Ephrin-B1 forward and reverse signaling are required during mouse development. Genes Dev 18: 572-583.

Davy A, Bush JO, Soriano P. 2006. Inhibition of gap junction communication at ectopic Eph/ephrin boundaries underlies craniofrontonasal syndrome. PLoS Biol 4: e315.

Desai RA, Gao L, Raghavan S, Liu WF, Chen CS. 2009. Cell polarity triggered by cell-cell adhesion via E-cadherin. J Cell Sci 122: 905-911.

Dravis C, Yokoyama N, Chumley MJ, Cowan CA, Silvany RE, Shay J, Baker LA, Henkemeyer M. 2004. Bidirectional signaling mediated by ephrin-B2 and EphB2 controls urorectal development. Dev Biol 271: 272-290.

Drees F, Pokutta S, Yamada S, Nelson WJ, Weis WI. 2005. $\alpha$-catenin is a molecular switch that binds E-cadherin- $\beta$-catenin and regulates actinfilament assembly. Cell 123: 903-915.

Dupin I, Camand E, Etienne-Manneville S. 2009. Classical cadherins control nucleus and centrosome position and cell polarity. J Cell Biol 185: 779-786.

Egea J, Klein R. 2007. Bidirectional Eph-ephrin signaling during axon guidance. Trends Cell Biol 17: 230-238.

Ehrlich JS, Hansen MD, Nelson WJ. 2002. Spatio-temporal regulation of Rac1 localization and lamellipodia dynamics during epithelial cell-cell adhesion. Dev Cell 3: 259-270.

Flenniken AM, Gale NW, Yancopoulos GD, Wilkinson DG. 1996. Distinct and overlapping expression patterns of ligands for Eph-related receptor tyrosine kinases during mouse embryogenesis. Dev Biol 179: $382-401$.

Foty RA, Steinberg MS. 2005. The differential adhesion hypothesis: A direct evaluation. Dev Biol 278: 255-263.

Fraser S, Keynes R, Lumsden A. 1990. Segmentation in the chick embryo hindbrain is defined by cell lineage restrictions. Nature 344: 431-435.
Fujita Y, Krause G, Scheffner M, Zechner D, Leddy HE, Behrens J, Sommer T, Birchmeier W. 2002. Hakai, a c-Cbl-like protein, ubiquitinates and induces endocytosis of the E-cadherin complex. Nat Cell Biol 4: 222-231.

Gale NW, Holland SJ, Valenzuela DM, Flenniken A, Pan L, Ryan TE, Henkemeyer M, Strebhardt K, Hirai H, Wilkinson DG, et al. 1996. Eph receptors and ligands comprise two major specificity subclasses and are reciprocally compartmentalized during embryogenesis. Neuron 17: 9-19.

Godt D, Tepass U. 1998. Drosophila oocyte localization is mediated by differential cadherin-based adhesion. Nature 395: 387-391.

Guo DL, Zhang J, Yuen ST, Tsui WY, Chan AS, Ho C, Ji J, Leung SY, Chen X. 2006. Reduced expression of EphB2 that parallels invasion and metastasis in colorectal tumours. Carcinogenesis 27: 454-464.

Guthrie S, Prince V, Lumsden A. 1993. Selective dispersal of avian rhombomere cells in orthotopic and heterotopic grafts. Development 118: 527-538.

Halbleib JM, Nelson WJ. 2006. Cadherins in development: Cell adhesion, sorting, and tissue morphogenesis. Genes Dev 20: 3199-3214.

Hansen MJ, Dallal GE, Flanagan JG. 2004. Retinal axon response to ephrin-As shows a graded, concentration-dependent transition from growth promotion to inhibition. Neuron 42: 717-730.

Harris AK. 1976. Is cell sorting caused by differences in the work of intercellular adhesion? A critique of the Steinberg hypothesis. J Theor Biol 61: $267-285$.

Harris TJ, Tepass U. 2010. Adherens junctions: From molecules to morphogenesis. Nat Rev Mol Cell Biol 11: 502-514.

Hattori M, Osterfield M, Flanagan JG. 2000. Regulated cleavage of a contact-mediated axon repellent. Science 289: 1360-1365.

Hatzis P, van der Flier LG, van Driel MA, Guryev V, Nielsen F, Denissov S, Nijman IJ, Koster J, Santo EE, Welboren W, et al. 2008. Genome-wide pattern of TCF7L2/TCF4 chromatin occupancy in colorectal cancer cells. Mol Cell Biol 28: 2732-2744.

Hazan RB, Kang L, Whooley BP, Borgen PI. 1997. N-cadherin promotes adhesion between invasive breast cancer cells and the stroma. Cell Adhes Commun 4: 399-411.

Hazan RB, Phillips GR, Qiao RF, Norton L, Aaronson SA. 2000. Exogenous expression of $\mathrm{N}$-cadherin in breast cancer cells induces cell $\mathrm{mi}-$ gration, invasion, and metastasis. J Cell Biol 148: 779-790.

Holland SJ, Gale NW, Mbamalu G, Yancopoulos GD, Henkemeyer M, Pawson T. 1996. Bidirectional signalling through the EPH-family receptor Nuk and its transmembrane ligands. Nature 383: 722-725.

Holmberg J, Clarke DL, Frisen J. 2000. Regulation of repulsion versus adhesion by different splice forms of an Eph receptor. Nature 408: 203-206.

Hornberger MR, Dutting D, Ciossek T, Yamada T, Handwerker C, Lang S, Weth F, Huf J, Wessel R, Logan C, et al. 1999. Modulation of EphA receptor function by coexpressed ephrinA ligands on retinal ganglion cell axons. Neuron 22: 731-742.

Inoue T, Chisaka O, Matsunami H, Takeichi M. 1997. Cadherin-6 expression transiently delineates specific rhombomeres, other neural tube subdivisions, and neural crest subpopulations in mouse embryos. Dev Biol 183: 183-194.

Inoue T, Tanaka T, Takeichi M, Chisaka O, Nakamura S, Noriko O. 2001. Role of cadherins in maintaining the compartment boundary between the cortex and striatum during development. Development 128: 561 569.

Irvine KD, Rauskolb C. 2001. Boundaries in development: Formation and function. Annu Rev Cell Dev Biol 17: 189-214.

Jamora C, Fuchs E. 2002. Intercellular adhesion, signalling and the cytoskeleton. Nat Cell Biol 4: E101-E108.

Janes PW, Saha N, Barton WA, Kolev MV, Wimmer-Kleikamp SH, Nievergall E, Blobel CP, Himanen JP, Lackmann M, Nikolov DB. 2005. Adam meets Eph: An ADAM substrate recognition module acts as a molecular switch for ephrin cleavage in trans. Cell 123: 291-304.

Jorgensen C, Sherman A, Chen GI, Pasculescu A, Poliakov A, Hsiung M, Larsen B, Wilkinson DG, Linding R, Pawson T. 2009. Cell-specific 
information processing in segregating populations of Eph receptor ephrin-expressing cells. Science 326: 1502-1509.

Jubb AM, Zhong F, Bheddah S, Grabsch HI, Frantz GD, Mueller W, Kavi V, Quirke P, Polakis P, Koeppen H. 2005. EphB2 is a prognostic factor in colorectal cancer. Clin Cancer Res 11: 5181-5187.

Julich D, Geisler R, Holley SA. 2005. Integrin $\alpha 5$ and $\delta /$ notch signaling have complementary spatiotemporal requirements during zebrafish somitogenesis. Dev Cell 8: 575-586.

Julich D, Mould AP, Koper E, Holley SA. 2009. Control of extracellular matrix assembly along tissue boundaries via Integrin and Eph/Ephrin signaling. Development 136: 2913-2921.

Kemp HA, Cooke JE, Moens CB. 2009. EphA4 and EfnB2a maintain rhombomere coherence by independently regulating intercalation of progenitor cells in the zebrafish neural keel. Dev Biol 327: 313-326.

Kiecker C, Lumsden A. 2005. Compartments and their boundaries in vertebrate brain development. Nat Rev Neurosci 6: 553-564.

Kim S-Y, Yamamoto A, Bouwmeester T, Aguis E, De Robertis EM. 1998. The role of paraxial protocadherin in selective adhesion and cell movements of the mesoderm during Xenopus gastrulation. Development 125: 4681-4691.

Kim SH, Jen WC, De Robertis EM, Kintner C. 2000. The protocadherin PAPC establishes segmental boundaries during somitogenesis in xenopus embryos. Curr Biol 10: 821-830.

Koshida S, Kishimoto Y, Ustumi H, Shimizu T, Furutani-Seiki M, Kondoh H, Takada S. 2005. Integrin $\alpha 5$-dependent fibronectin accumulation for maintenance of somite boundaries in zebrafish embryos. Dev Cell 8: $587-598$.

Krasnoperov V, Kumar SR, Ley E, Li X, Scehnet J, Liu R, Zozulya S, Gill PS. 2010. Novel EphB4 monoclonal antibodies modulate angiogenesis and inhibit tumor growth. Am J Pathol 176: 2029-2038.

Krieg M, Arboleda-Estudillo Y, Puech PH, Kafer J, Graner F, Muller DJ, Heisenberg CP. 2008. Tensile forces govern germ-layer organization in zebrafish. Nat Cell Biol 10: 429-436.

Kullander K, Klein R. 2002. Mechanisms and functions of Eph and ephrin signalling. Nat Rev Mol Cell Biol 3: 475-486.

Kumar SR, Singh J, Xia G, Krasnoperov V, Hassanieh L, Ley EJ, Scehnet J, Kumar NG, Hawes D, Press MF, et al. 2006. Receptor tyrosine kinase EphB4 is a survival factor in breast cancer. Am J Pathol 169: 279-293.

Landsberg KP, Farhadifar R, Ranft J, Umetsu D, Widmann TJ, Bittig T, Said A, Julicher F, Dahmann C. 2009. Increased cell bond tension governs cell sorting at the Drosophila anteroposterior compartment boundary. Curr Biol 19: 1950-1955.

Langenberg T, Brand M. 2005. Lineage restriction maintains a stable organizer cell population at the zebrafish midbrain-hindbrain boundary. Development 132: 3209-3216.

Leckband D, Prakasam A. 2006. Mechanism and dynamics of cadherin adhesion. Annu Rev Biomed Eng 8: 259-287.

Lecuit T, Lenne PF. 2007. Cell surface mechanics and the control of cell shape, tissue patterns and morphogenesis. Nat Rev Mol Cell Biol 8: 633-644.

Lee HS, Nishanian TG, Mood K, Bong YS, Daar IO. 2008. EphrinB1 controls cell-cell junctions through the Par polarity complex. Nat Cell Biol 10: $979-986$.

Libusova L, Stemmler MP, Hierholzer A, Schwarz H, Kemler R. 2010. $\mathrm{N}$-cadherin can structurally substitute for E-cadherin during intestinal development but leads to polyp formation. Development 137: $2297-2305$.

Machado JC, Oliveira C, Carvalho R, Soares P, Berx G, Caldas C, Seruca R, Carneiro F, Sobrinho-Simoes M. 2001. E-cadherin gene (CDH1) promoter methylation as the second hit in sporadic diffuse gastric carcinoma. Oncogene 20: 1525-1528.

Major RJ, Irvine KD. 2005. Influence of Notch on dorsoventral compartmentalization and actin organization in the Drosophila wing. Development 132: 3823-3833.

Major RJ, Irvine KD. 2006. Localization and requirement for Myosin II at the dorsal-ventral compartment boundary of the Drosophila wing. Dev Dyn 235: 3051-3058.
Makrilia N, Kollias A, Manolopoulos L, Syrigos K. 2009. Cell adhesion molecules: Role and clinical significance in cancer. Cancer Invest 27: $1023-1037$.

Marston DJ, Dickinson S, Nobes CD. 2003. Rac-dependent transendocytosis of ephrinBs regulates Eph-ephrin contact repulsion. Nat Cell Biol 5: 879-888.

Matsunami H, Takeichi M. 1995. Fetal brain subdivisions defined by Rand E-cadherin expressions: Evidence for the role of cadherin activity in region-specific, cell-cell adhesion. Dev Biol 172: 466-478.

Mellitzer G, Xu Q, Wilkinson DG. 1999. Eph receptors and ephrins restrict cell intermingling and communication. Nature 400: 77-81.

Milan M, Weihe U, Perez L, Cohen SM. 2001. The LRR proteins capricious and Tartan mediate cell interactions during DV boundary formation in the Drosophila wing. Cell 106: 785-794.

Monier B, Pelissier-Monier A, Brand AH, Sanson B. 2010. An actomyosin-based barrier inhibits cell mixing at compartmental boundaries in Drosophila embryos. Nat Cell Biol 12: 61-69.

Monier B, Pelissier-Monier A, Sanson B. 2011. Establishment and maintenance of compartmental boundaries: Role of contractile actomyosin barriers. Cell Mol Life Sci 68: 1897-1910.

Moore R, Cai KQ, Escudero DO, Xu XX. 2009. Cell adhesive affinity does not dictate primitive endoderm segregation and positioning during murine embryoid body formation. Genesis 47: 579-589.

Morishita H, Yagi T. 2007. Protocadherin family: Diversity, structure, and function. Curr Opin Cell Biol 19: 584-592.

Munarini N, Jager R, Abderhalden S, Zuercher G, Rohrbach V, Loercher S, Pfanner-Meyer B, Andres AC, Ziemiecki A. 2002. Altered mammary epithelial development, pattern formation and involution in transgenic mice expressing the EphB4 receptor tyrosine kinase. J Cell Sci 115: $25-37$.

Nieman MT, Prudoff RS, Johnson KR, Wheelock MJ. 1999. N-cadherin promotes motility in human breast cancer cells regardless of their Ecadherin expression. J Cell Biol 147: 631-644.

Niessen CM, Gumbiner BM. 2002. Cadherin-mediated cell sorting not determined by binding or adhesion specificity. J Cell Biol 156: $389-$ 399.

Nieto MA, Gilardi-Hebenstreit P, Charnay P, Wilkinson DG. 1992. A receptor protein tyrosine kinase implicated in the segmental patterning of the hindbrain and mesoderm. Development 116: 1137-1150.

Ninomiya H, Winklbauer R. 2008. Epithelial coating controls mesenchymal shape change through tissue-positioning effects and reduction of surface-minimizing tension. Nat Cell Biol 10: 61-69.

Noren NK, Pasquale EB. 2007. Paradoxes of the EphB4 receptor in cancer. Cancer Res 67: 3994-3997.

Noren NK, Foos G, Hauser CA, Pasquale EB. 2006. The EphB4 receptor suppresses breast cancer cell tumorigenicity through an Abl-Crk pathway. Nat Cell Biol 8: 815-825.

Nose A, Nagafuchi A, Takeichi M. 1988. Expressed recombinant cadherins mediate cell sorting in model systems. Cell 54: 993-1001.

Paluch E, Heisenberg CP. 2009. Biology and physics of cell shape changes in development. Curr Biol 19: R790-R799.

Park KS, Gumbiner BM. 2010. Cadherin 6B induces BMP signaling and de-epithelialization during the epithelial mesenchymal transition of the neural crest. Development 137: 2691-2701.

Pasquale EB. 2005. Eph receptor signalling casts a wide net on cell behaviour. Nat Rev Mol Cell Biol 6: 462-475.

Patel SD, Ciatto C, Chen CP, Bahna F, Rajebhosale M, Arkus N, Schieren I, Jessell TM, Honig B, Price SR, et al. 2006. Type II cadherin ectodomain structures: Implications for classical cadherin specificity. Cell 124: $1255-1268$.

Poliakov A, Cotrina M, Wilkinson DG. 2004. Diverse roles of eph receptors and ephrins in the regulation of cell migration and tissue assembly. Dev Cell 7: 465-480.

Poliakov A, Cotrina ML, Pasini A, Wilkinson DG. 2008. Regulation of EphB2 activation and cell repulsion by feedback control of the MAPK pathway. J Cell Biol 183: 933-947. 
Price SR, De Marco Garcia NV, Ranscht B, Jessell TM. 2002. Regulation of motor neuron pool sorting by differential expression of type II cadherins. Cell 109: 205-216.

Rebsam A, Mason CA. 2011. Cadherins as matchmakers. Neuron 71: 566-568.

Redies C, Takeichi M. 1996. Cadherins in the developing central nervous system: An adhesive code for segmental and functional subdivisions. Dev Biol 180: 413-423.

Reintsch WE, Habring-Mueller A, Wang RW, Schohl A, Fagotto F. 2005. $\beta$-Catenin controls cell sorting at the notochord-somite boundary independently of cadherin-mediated adhesion. J Cell Biol 170: 675-686.

Rhee J, Takahashi Y, Saga Y, Wilson-Rawls J, Rawls A. 2003. The protocadherin papc is involved in the organization of the epithelium along the segmental border during mouse somitogenesis. Dev Biol 254: 248-261.

Rieger S, Senghaas N, Walch A, Koster RW. 2009. Cadherin-2 controls directional chain migration of cerebellar granule neurons. PLoS Biol 7: e1000240.

Rohani N, Canty L, Luu O, Fagotto F, Winklbauer R. 2011. EphrinB/ EphB signaling controls embryonic germ layer separation by contact-induced cell detachment. PLoS Biol 9: e1000597.

Roura S, Miravet S, Piedra J, Garcia de Herreros A, Dunach M. 1999. Regulation of E-cadherin/catenin association by tyrosine phosphorylation. J Biol Chem 274: 36734-36740.

Shi Q, Chien YH, Leckband D. 2008. Biophysical properties of cadherin bonds do not predict cell sorting. J Biol Chem 283: 28454-28463.

Sobieszczuk DF, Wilkinson DG. 1999. Masking of Eph receptors and ephrins. Curr Biol 9: R469-R470.

Solanas G, Cortina C, Sevillano M, Batlle E. 2011. Cleavage of E-cadherin by ADAM10 mediates epithelial cell sorting downstream of EphB signalling. Nat Cell Biol 13: 1100-1107.

Solnica-Krezel L. 2006. Gastrulation in zebrafish-All just about adhesion? Curr Opin Genet Dev 16: 433-441.

Steinberg MS. 1963. Reconstruction of tissues by dissociated cells. Some morphogenetic tissue movements and the sorting out of embryonic cells may have a common explanation. Science 141: 401-408.

Steinberg MS. 1970. Does differential adhesion govern self-assembly processes in histogenesis? Equilibrium configurations and the emergence of a hierarchy among populations of embryonic cells. J Exp Zool 173: 395-433.

Steinberg MS. 2007. Differential adhesion in morphogenesis: A modern view. Curr Opin Gen Dev 17: 281-286.

Steinberg MS, Takeichi M. 1994. Experimental specification of cell sorting, tissue spreading, and specific spatial patterning by quantitative differences in cadherin expression. Proc Natl Acad Sci 91: 206-209.

Suyama K, Shapiro I, Guttman M, Hazan RB. 2002. A signaling pathway leading to metastasis is controlled by N-cadherin and the FGF receptor. Cancer Cell 2: 301-314.

Takeichi M, Uemura T, Iwai Y, Uchida N, Inoue T, Tanaka T, Suzuki SC. 1997. Cadherins in brain patterning and neural network formation. Cold Spring Harb Symp Quant Biol 62: 505-510.

Takeichi M, Nakagawa S, Aono S, Usui T, Uemura T. 2000. Patterning of cell assemblies regulated by adhesion receptors of the cadherin superfamily. Philos T Roy Soc B 355: 885-890.
Tanaka M, Kamo T, Ota S, Sugimura H. 2003. Association of dishevelled with Eph tyrosine kinase receptor and ephrin mediates cell repulsion. EMBO J 22: 847-858.

Theveneau E, Marchant L, Kuriyama S, Gull M, Moepps B, Parsons M, Mayor R. 2010. Collective chemotaxis requires contact-dependent cell polarity. Dev Cell 19: 39-53.

Thiery JP, Acloque H, Huang RY, Nieto MA. 2009. Epithelial-mesenchymal transitions in development and disease. Cell 139: 871-890.

Townes PL, Holtfreter J. 1955. Directed movements and selective adhesion of embryonic amphibian cells. J Exp Zool 128: 53-120.

Tran NL, Nagle RB, Cress AE, Heimark RL. 1999. N-Cadherin expression in human prostate carcinoma cell lines. An epithelial-mesenchymal transformation mediating adhesion with stromal cells. Am J Pathol 155: 787-798.

van Roy F, Berx G. 2008. The cell-cell adhesion molecule E-cadherin. Cell Mol Life Sci 65: 3756-3788.

von der Hardt S, Bakkers J, Inbal A, Carvalho L, Solnica-Krezel L, Heisenberg CP, Hammerschmidt M. 2007. The Bmp gradient of the zebrafish gastrula guides migrating lateral cells by regulating cell-cell adhesion. Curr Biol 17: 475-487.

Weber GF, Bjerke MA, DeSimone DW. 2011. Integrins and cadherins join forces to form adhesive networks. J Cell Sci 124: 1183-1193.

Williams EJ, Williams G, Howell FV, Skaper SD, Walsh FS, Doherty P. 2001. Identification of an N-cadherin motif that can interact with the fibroblast growth factor receptor and is required for axonal growth. J Biol Chem 276: 43879-43886.

Winklbauer R. 2009. Cell adhesion in amphibian gastrulation. Int Rev Cell Mol Biol 278: 215-275.

Xu Q, Alldus G, Holder N, Wilkinson DG. 1995. Expression of truncated Sek-1 receptor tyrosine kinase disrupts the segmental restriction of gene expression in the Xenopus and zebrafish hindbrain. Development 121: 4005-4016.

Xu Q, Mellitzer G, Robinson V, Wilkinson DG. 1999. In vivo cell sorting in complementary segmental domains mediated by Eph receptors and ephrins. Nature 399: 267-271.

Yagi T, Takeichi M. 2000. Cadherin superfamily genes: Functions, genomic organization, and neurologic diversity. Genes Dev 14: 11691180.

Yamada S, Nelson WJ. 2007. Localized zones of Rho and Rac activities drive initiation and expansion of epithelial cell-cell adhesion. J Cell Biol 178: 517-527.

Yamada S, Pokutta S, Drees F, Weis WI, Nelson WJ. 2005. Deconstructing the cadherin-catenin-actin complex. Cell 123: 889-901.

Yin Y, Yamashita Y, Noda H, Okafuji T, Go MJ, Tanaka H. 2004. EphA receptor tyrosine kinases interact with co-expressed ephrin-A ligands in cis. Neurosci Res 48: 285-296.

Zeltser LM, Larsen CW, Lumsden A. 2001. A new developmental compartment in the forebrain regulated by lunatic fringe. Nat Neurosci 4: $683-684$.

Zimmer M, Palmer A, Kohler J, Klein R. 2003. EphB-ephrinB bi-directional endocytosis terminates adhesion allowing contact mediated repulsion. Nat Cell Biol 5: 869-878. 


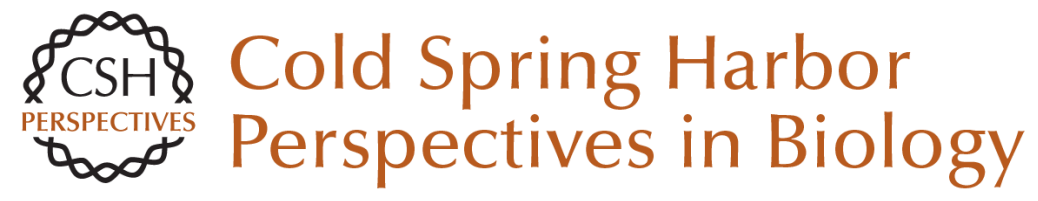

\section{Molecular Mechanisms of Cell Segregation and Boundary Formation in Development and Tumorigenesis}

Eduard Batlle and David G. Wilkinson

Cold Spring Harb Perspect Biol 2012; doi: 10.1101/cshperspect.a008227

Subject Collection Mammalian Development

The Dynamics of Morphogenesis in the Early

Mouse Embryo

Jaime A. Rivera-Pérez and Anna-Katerina

Hadjantonakis

microRNAs as Developmental Regulators Kathryn N. Ivey and Deepak Srivastava

Development of the Endochondral Skeleton Fanxin Long and David M. Ornitz

Adipogenesis

Kelesha Sarjeant and Jacqueline M. Stephens

Molecular Mechanisms of Inner Ear Development

Doris K. Wu and Matthew W. Kelley

Polarity in Mammalian Epithelial Morphogenesis Julie Roignot, Xiao Peng and Keith Mostov

Eye Development and Retinogenesis Whitney Heavner and Larysa Pevny

Primordial Germ Cells in Mice

Mitinori Saitou and Masashi Yamaji

Cell Division Modes and Cleavage Planes of

Neural Progenitors during Mammalian Cortical

Development

Fumio Matsuzaki and Atsunori Shitamukai

Blood and Lymphatic Vessel Formation

Victoria L. Bautch and Kathleen M. Caron

Transcriptional Networks in Liver and Intestinal

Development

Karyn L. Sheaffer and Klaus H. Kaestner

Pluripotency in the Embryo and in Culture Jennifer Nichols and Austin Smith

Signaling and Transcriptional Networks in Heart

Development and Regeneration

Benoit G. Bruneau

Signals and Switches in Mammalian Neural Crest

Cell Differentiation

Shachi Bhatt, Raul Diaz and Paul A. Trainor

Hematopoiesis

Michael A. Rieger and Timm Schroeder

Intercellular Interactions, Position, and Polarity in

Establishing Blastocyst Cell Lineages and

Embryonic Axes

Robert O. Stephenson, Janet Rossant and Patrick

P.L. Tam

For additional articles in this collection, see http://cshperspectives.cshlp.org/cgi/collection/

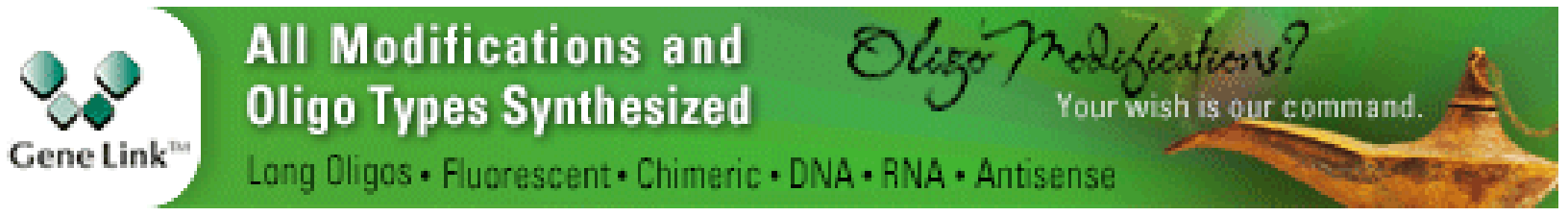

Copyright @ 2012 Cold Spring Harbor Laboratory Press; all rights reserved 
For additional articles in this collection, see http://cshperspectives.cshlp.org/cgi/collection/

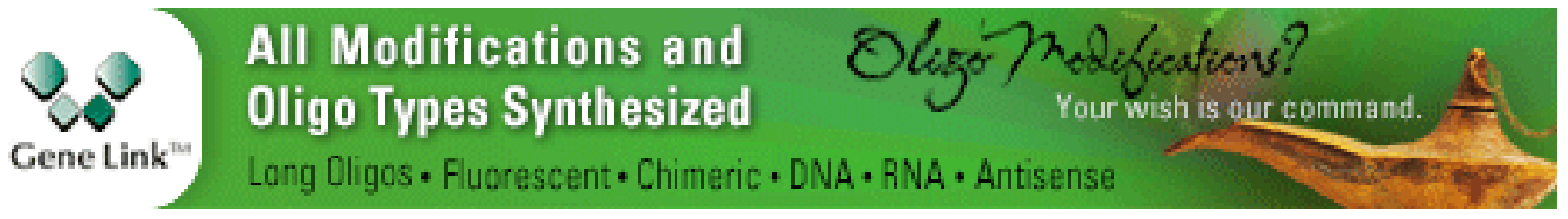

Copyright @ 2012 Cold Spring Harbor Laboratory Press; all rights reserved 